\title{
COMPORTAMENTO DA TIRIRICA (Cyperus rotundus) SOB DIFERENTES NÍVEIS DE ADUBAÇÃO FOSFATADA E DE SOMBREAMENTO ${ }^{1}$
}

\author{
MARTA C.M. NEMOTO ${ }^{2}$, PEDRO L.C.A. ALVES ${ }^{3}$, ROBINSON A. PITELLI ${ }^{4}$ e LUIZ R.P. NEMOTO ${ }^{2}$
}

\begin{abstract}
O trabalho, instalado e conduzido em casa de vegetação da FCAV, Campus de Jaboticabal, UNESP, teve por objetivos estudar os efeitos de diferentes doses de adubação fosfatada $(0,33,5,67,0$ e 100,5 ppm de P20s) e níveis de sombreamento $(0,30,50$ e $70 \%)$ sobre parâmetros de crescimento de tiririca (Cyperus rotundus). Quatro tubérculos previamente brotados foram colocados em cada vaso com capacidade para três litros de solo. Utilizou-se Latossolo Vermelho-Escuro, textura média, moderado, distrófico, peneirado. Para efeito de análise estatística, os vasos (parcelas) foram dispostos num esquema inteiramente casualisado, com quatro repetições. Os resultados obtidos mostraram o efeito prejudicial do sombreamento sobre o desenvolvimento
\end{abstract}

RESUMO

da tiririca. Já ao nível de 30\%, o sombreamento causou redução na densidade das plantas, principalmente por reduzir o número de bulbos + tubérculos. Em consequência, houve redução no acúmulo de matéria seca nas diferentes partes da planta, redução esta mais acentuada no sistema subterrâneo (bulbos + tubérculos + raízes), causando incremento nas relações $\mathrm{PA} / \mathrm{B}+\mathrm{T}+\mathrm{R}$ e $\mathrm{B}+\mathrm{T} / \mathrm{R}$. A adubação fosfatada, no entanto, incrementou os parâmetros de crescimento da espécie, principalmente no desenvolvimento das manifestações epígeas, refletido tanto pelo aumento em número quanto em acúmulo de matéria seca.

Palavras-chave: Biologia, alocação de recursos.

\section{ABSTRACT \\ Study of purple nutsedge (Cyperus rotundus) under levels of phosphoric fertilization andshading}

This research was carried out under greenhouse conditions at the College of Agriculture, Campus of Jaboticabal, UNESP, with the objective of studying the effects of different levels of phosphoric fertilization $(0,33.5,67.0$ and $100.5 \mathrm{ppm}$ P20s) and shading levels $(0,30,50$ and $70 \%$ of light interception) on some growth parameters of purple nutsedge (Cyperus rotundus). The tubers emerged were placed (in numbers of 4) in plastic pots containing three liters of Dark Red Latossoil (soil), medium texture, being previously screened. The experiment was land out in a completely randomized design with four replications. The results showed the detrimental effect of shading on purple nutsedge development; at a level of $30 \%$ shading there was a reduction in plant density, mainly due to a reduction in the numbers of bulbs and tubers. As a consequence there was a reduction in the dry matter accumulation in the subterranean parts (bulbs, tubers and roots), causing an increase in the ratios $\mathrm{PA} / \mathrm{B}+\mathrm{T}+\mathrm{R}$ and $\mathrm{B}+\mathrm{T} / \mathrm{R}$. Phosphoric fertilization, however, increased the growth parameters of the species, mainly in the development of the PA by an increase in the number and dry matter accumulation.

Additional index words: Biology.

1 Recebido para publicação em 17/10/94 e na forma revisada em 28/04/95.

2 Ene Agr ${ }^{\circ}$, Pós-graduando, Depto. de Biologia Aplicada, Faculdade de Ciências Agrárias e Veterinárias, UNESP, Rod. Carlos Tonanni, km 5,

Jaboticabal, SP 14870-000

3 Professor Assistente, Depto. de Biologia Aplicada, FCAVJ-UNESP, Rod. Carlos Tonanni, km 5, Jaboticabal, SP $14870-000$

4 Professor Adjunto, Depto. de Biologia Aplicada, FCAVJ-UNESP, Rod. Carlos Tonanni, km 5, Jaboticabal, SP $14870-000$ 


\section{INTRODUÇÃO}

A tiririca (Cyperus rotundus L.) é uma das principais plantas infestantes de culturas agrícolas em todo o mundo, aonde a sua interferência tem causado reduções quantitativas e qualitativas na produção, principalmente nas regiões tropical e subtropical (Holm et al., 1977).

Considerando que a tiririca é uma espécie de baixo porte epígeo, acreditase que sua interferência seja predominantemente a nível edáfico, principalmente na fase inicial de convivência, quando a planta daninha ainda recebe grande quantidade de luz e pode manifestar todo seu potencial de crescimento e recrutamento de recursos do meio.

Patterson (1984) verificou que o sombreamento da tiririca faz decrescer a partição de biomassa para os tubérculos e rizomas, porém aumenta nas folhas. Visto esta característica negativa da tiririca, qualquer prática de manejo que promova um fechamento mais cedo das folhagens das culturas (diminuição do espaçamento, adubação na linha, etc.) serão medidas úteis para diminuir a interferência desta planta daninha, bem como a utilização em sistemas de manejo integrado.

A diferenciação do rizoma em tubérculos e bulbos basais é influenciada pelos fatores ambientais como fotoperíodo, temperatura, umidade e propriedades do solo, principalmente fertilidade que está diretamente relacionada à prática de adubação (Garg, 1968).

Vários estudos têm evidenciado que em algumas situações ambientais, especialmente naquelas que lhe conferem estresse, a tiririca muda seu padrão de alocação de recursos, ora incrementando o esforço reprodutivo, ora o vegetativo. $\mathrm{O}$ sombreamento de plantas de tiririca, realizado pelo dossel de plantas com maior porte, reduz muito sua competitividade (Magalhães, 1967) e aplicações de fósforo refletem em aumento numérico de manifestações epígeas (Pam, 1977). Todos esses fatores mencionados poderão interferir na dinâmica populacional da espécie e em suas características fisiológicas e morfológicas, deixandoa predisposta às medidas de controle empregadas. Siriwardana e Nishimoto (1987) relataram que o conhecimento da distribuição, e frequência de diferentes tipos de bulbos basais e do desenvolvimento da tiririca é necessário para um melhor manejo desta planta daninha com glifosato ou outro herbicida.

Deste modo, o presente trabalho objetivou estudar os efeitos da adubação fosfatada e do sombreamento sobre a produção de manifestações epígeas e de tubérculos de tiririca, bem como os efeitos sobre a participação de biomasssa em raízes, tubérculos, bulbos basais e manifestações epígeas.

\section{MATERIAL E MÉTODOS}

O presente trabalho foi instalado e conduzido em casade-vegetação no Departamento de Biologia Aplicada à Agropecuária, da Faculdade de Ciências Agrárias e Veterinárias, Campus de Jaboticabal, UNESP.

O solo foi coletado na camada arável $(0-20 \mathrm{~cm})$ de um Latossolo VermelhoEscuro, textura média, distrófico e A moderado, apresentando 2,5\% de matéria orgânica, 5,0 $\mathrm{mg} / \mathrm{cm}$ de fósforo e $35 \%$ de saturação de base. Foi realizada correção de acidez aos 83 dias antes do plantio de modo a elevar a porcentagem de saturação de bases para $60 \%$, uma vez que este é o valor médio indicado para a maioria das culturas, adicionando-se calcário dolomítico em quantidade equivalente a 1,97 t/ha. Esta adição foi feita individualmente, adicionando-se 2,95 g de calcário por vaso.

Os tubérculos da tiririca (Cyperus rotundus L.), coletados em área infestada da FCAVJ, foram selecionados quanto ao tamanho e postos para brotar em câmara de crescimento, com fotoperíodo de 14 horas, intensidade luminosa da 108 $\mu \mathrm{Em}^{-2} \mathrm{~s}^{-2}$ e temperatura de $25,0^{\circ} \mathrm{C} \pm 2$, em caixas plásticas contendo areia. Após a brotação, os tubérculos que apresentaram, em média, duas manifestações epígeas, foram transferidos, em número de quatro aos vasos plásticos (amarelos) com capacidade para três litros de solo. Procurouse manter a umidade do solo mediante irrigações periódicas, de forma que todos ficassem visualmente úmidos.

Os tratamentos foram constituídos de quatro doses de fósforo (P205),a saber: 0, 33,5, 67,0 e 100,5 ppm, combinados com quatro níveis de sombreamento: 0, 30, 50 e 70\%, perfazendo um total de 16 tratamentos. As doses de fósforo foram aplicadas de acordo com análise preliminar (sendo a dose 0 ppm referente ao nível original de fósforo existente no solo que era de 5 ppm, considerado muito baixo), utilizandose, para tal, superfosfato triplo (45\% P205). Para obten ção dos referidos sombreamentos utilizouse telas sombrite. Mediu-se a intensidade luminosa e o coeficiente de extinção com o auxílio de luxímetro DR. LANGE modelo Standard, sob as telas de sombrite, dentro e fora da casa de vegetação de tal forma a conhecer a porcentagem real de extinção de luz.

A intensidade luminosa fora da casa de vegetação foi de 84000 Lux, ou seja, 14,28\% maior do que o nível 0\% de sombreamento no interior da casa de vegetação. A temperatura média do ar no interior da casa de vegetação situou-se em $28,07^{\circ} \mathrm{C} \pm 2,9$.

Decorrido um mês da instalação do trabalho, foi realizada uma adubação de cobertura com uréia $2 \%$, dissolvida em água, em todos os tratamentos.

$\mathrm{O}$ delineamento experimental utilizado foi o inteiramente ao acaso, com quatro repetições. Os tratamentos experimentais foram dispostos em esquema fatorial $4 \mathrm{x} 4$, onde constituíram variáveis: as quatro doses de fósforo e os quatro níveis de sombreamento já citados.

Dois meses após a instalação do experimento, foi feita a amostragem, quando então avaliaramse: o número de manifestações epígeas e de tubérculos e a matéria seca acumulada em manifestações epígeas, tubérculos e raízes.

A matéria seca das diferentes partes da planta foi obtida após secagem do material vegetal em estufa de circulação forçada de ar, à $75^{\circ} \mathrm{C}$, até peso constante.

Os resultados obtidos foram submetidos à análise de variância pelo teste $\mathrm{F}$ e comparação de médias feita pelo teste de Tukey a $5 \%$ de probabilidade, além do desdobramento dos graus de liberdade dos efeitos das variáveis principais do fatorial proposto e desdobramento da interação entre os níveis dos fatores. 


\section{RESULTADOS E DISCUSSÃO}

Pela análise estatística não se observou efeito da interação do sombreamento com a adubação fosfatada sobre o número de manifestações epígeas mas apenas efeito isolado destes fatores.

Com o aumento no nível de sombreamento, houve redução no número de manifestações epígeas, sendo que a partir de $50 \%$ de sombreamento esta redução foi significativa, diferindo dos níveis 0 e $30 \%$ de sombreamento. O número médio de manifestações epígeas aumentou a partir de 33,5 ppm de $\mathrm{P}_{2} \mathrm{O}_{5}(\mathrm{P})$, sem se constatar diferenças entre as doses de $\mathrm{P}$ adicionadas (Figuras 1 e 2). Para o número de bulbos + tubérculos, constatou-se efeito da interação entre os fatores principais. Neste caso, pela Figura 3, observa-se que até $30 \%$ de sombreamento, a tiririca respondeu à adubação fosfatada, aumentando o número de bulbos + tubérculos já a partir da dose de 33,5 ppm de $\mathrm{P}$, sendo que a $0 \%$ de sombreamento não houve diferenças entre os efeitos das doses e, a $30 \%$ de sombreamento, a dose de 100,5 ppm de $\mathrm{P}$ proporcionou maior aumento no número de bulbos + tubérculos. Nos níveis de 50 e $70 \%$ de sombreamento, não houve mais efeito das doses de $\mathrm{P}$ sobre o número de bulbos + tubérculos. Dentro das doses de $\mathrm{P}$, observouse redução no número de bulbos + tubérculos já a partir do nível de $30 \%$ de sombreamento, à exceção da dose de 100,5 ppm, quando a redução ocorreu apenas a partir do nível de $50 \%$ de sombreamento.

Com relação ao peso de matéria seca de manifestações epígeas não se constatou, novamente, efeito da interação entre o sombreamento e a adubação fosfatada, mas apenas dos fatores principais. Como pode-se observar pela Figura 4, os níveis de 50 e $70 \%$ de sombreamento reduziram o peso da matéria seca de manifestações epígeas de tiririca. Por outro lado, a adubação fosfatada proporcionou incremento neste

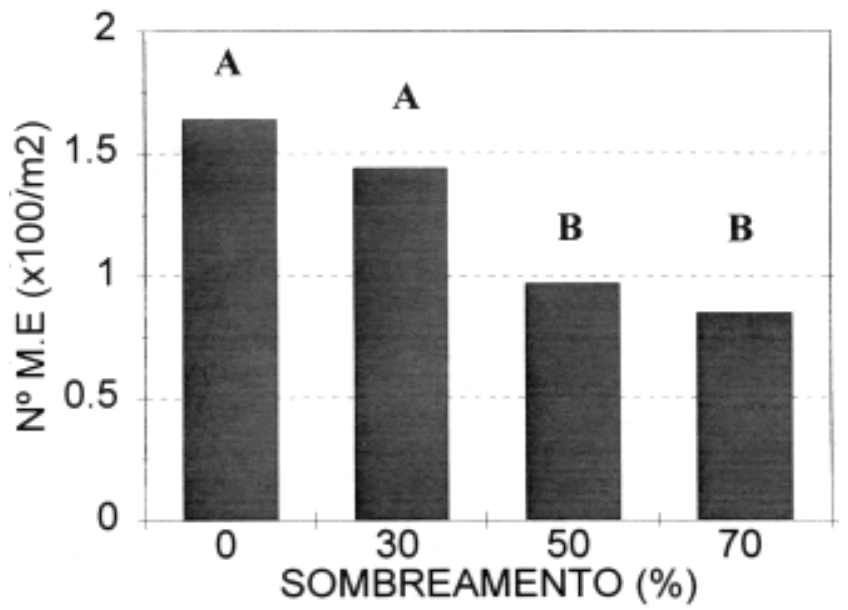

\section{MANIFESTAÇŐES EPÍGEAS}

FIG. 1- Número médio de manifestações epígeas em função do sombreamento. Barras com mesma letra não diferem entre si pelo teste Tukey ao nível de $5 \%$ de probabilidade. parâmetro já a partir de 33,5 ppm de $\mathrm{P}$, não havendo diferenças entre doses adicionadas (Figura 5).

Pela Figura 6, pode-se observar que houve a interação entre os fatores, sendo que nas plantas expostas aos níveis de 0 e $30 \%$ de sombreamento, a adubação fosfatada proporcionou aumento no peso de matéria seca de bulbos + tubérculos. A $0 \%$ de sombreamento, observou-se que o maior peso da matéria seca de bulbos + tubérculos ocorreu quando se utilizou a dose de 67,0 ppm de $\mathrm{P}$, enquanto a $30 \%$ de sombreamento este efeito foi observado a partir desta dose. Nos níveis de 50 e $70 \%$ de sombreamento, não mais se observou efeito da adubação fosfatada sobre este parâmetro. O sombreamento nos níveis de 50 e $70 \%$ reduziram igualmente o

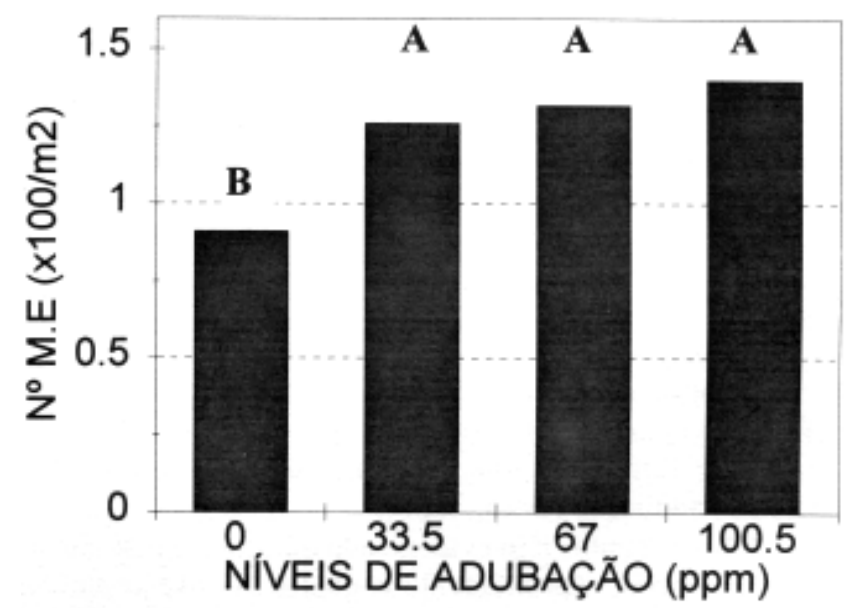

\section{MANIFESTAÇÕES EPÍGEAS}

FIG. 2 - Número médio de manifestações epígeas em função da adubação. Barras com mesma letra não diferem entre si pelo teste Tukey ao nível de $5 \%$ de probabilidade.

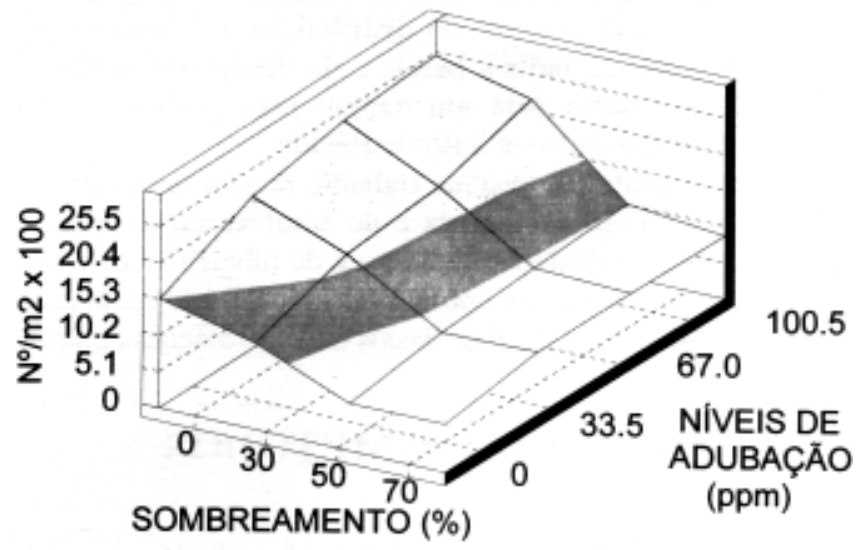

FIG. 3 - Efeito da interação entre os níveis de sombreamento e de adubação sobre o número de bulbos+tubérculos de tiririca. Pontos que se encontram sob mesmo padrão não diferem entre si pelo teste Tukey ao nível de $5 \%$ de probabilidade. 


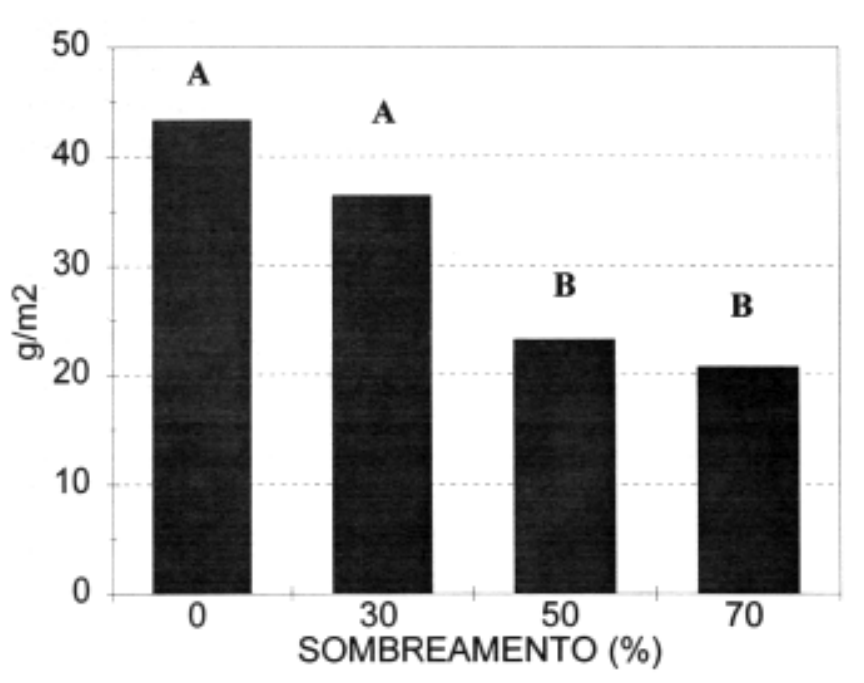

FIG. 4 - Peso da matéria seca de manifestações epígeas em função dos níveis sombreamento. Barras com mesma letra não diferem entre si pelo teste Tukey ao nível de $5 \%$ de probabilidade.

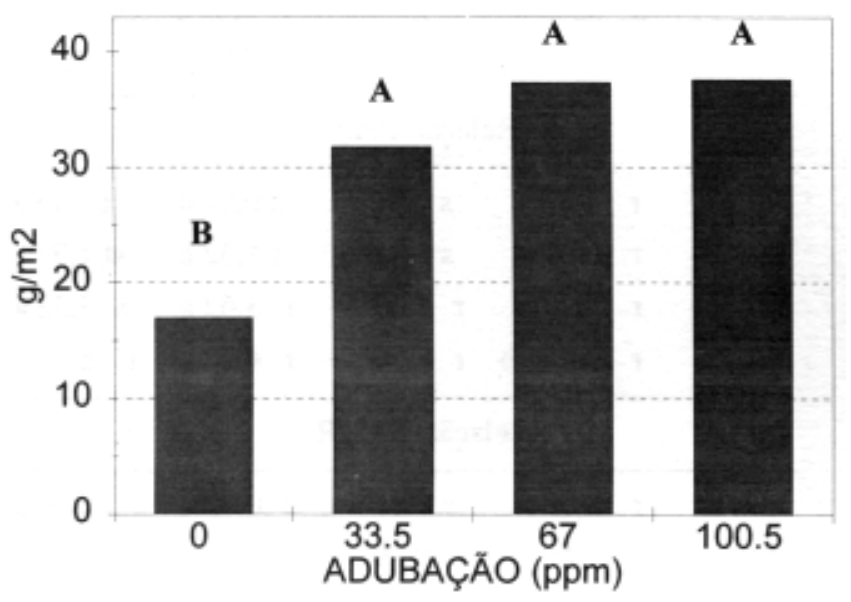

FIG. 5 - Peso da matéria seca de manifestações epígeas em função dos níveis adubação. Barras com mes ma letra não diferem entre si pelo teste Tukey ao nível de $5 \%$ de probabilidade.

peso da matéria seca de bulbos + tubérculos, independente da dose de $\mathrm{P}$ adicionada, sendo esta redução mais acentuada quando comparada à de $30 \%$.

A adição de $\mathrm{P}$ nas doses de 33,5 e 67,0 ppm aumentou o peso de matéria seca de raízes de plantas de tiririca que não foram submetidas ao sombreamento (Figura 7). No nível de $30 \%$ de sombreamento, a adição de fósforo já a partir da dose de 33,5 ppm acarretou em aumento neste parâmetro, porém sem existir diferenças significativas entre as doses adicionadas. Nos maiores níveis de sombreamento não houve efeito da adubação fosfatada. O sombreamento, a partir de $50 \%$, acarretou redução no peso, independente da dose de $\mathrm{P}$ empregada, sendo que nas menores doses, esta redução iniciou desde o nível de $30 \%$ de sombreamento.

As Tabelas 1 e 2 mostram os efeitos dos níveis de sombreamento e das doses de fósforo sobre as relações parte
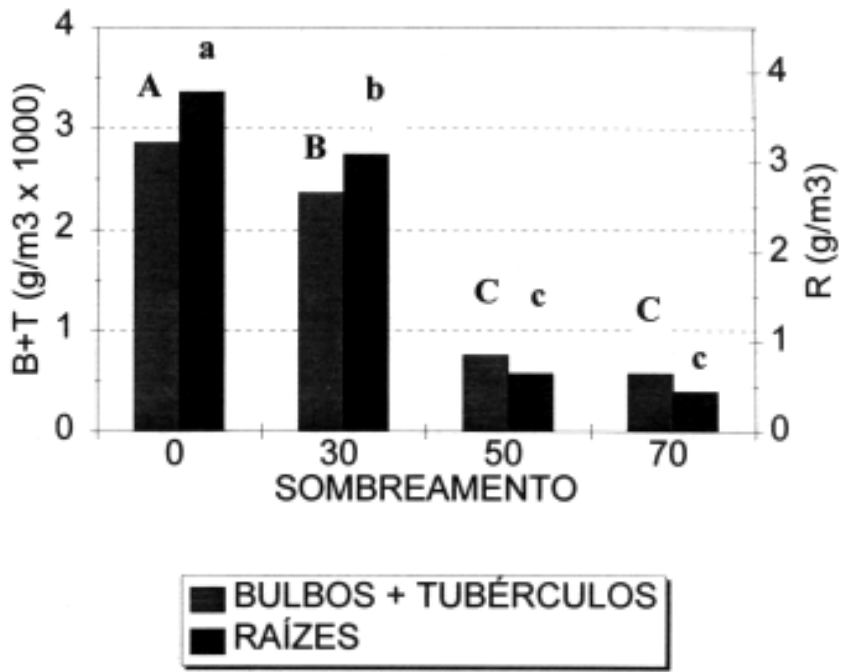

FIG. 6 - Peso da matéria seca de bulbos+tubérculos e raízes em função dos níveis sombreamento. Barras com mesma letra não diferem entre si pelo teste Tukey ao nível de $5 \%$ de probabilidade.

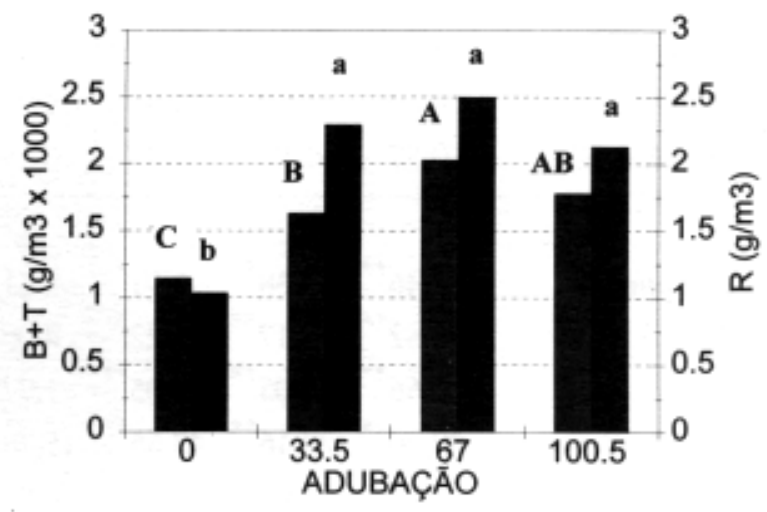

\section{BULBOS+TUBÉRCULOS $\square$ RAIZZES}

FIG. 7 - Peso da matéria seca de bulbos+tubérculos e raízes em função dos níveis adubação. Barras com mesma letra não diferem entre si pelo teste Tukey ao nível de $5 \%$ de probabilidade.

aérea / bulbos+tubérculos+raízes $(\mathrm{PA} / \mathrm{B}+\mathrm{T}+\mathrm{R})$, parte aérea / bulbos+tubérculos $(\mathrm{PA} / \mathrm{B}+\mathrm{T})$, parte aérea / raízes $(\mathrm{PA} / \mathrm{R}) \mathrm{e}$ bulbos+tubérculos / raízes $(\mathrm{B}+\mathrm{T} / \mathrm{R})$ de tiririca. Como comequência da redução mais acentuada no peso de matéria seca em raízes de tiririca decorrente do aumento do sombreamento, constatouse incremento na relação PA/R, principalmente nos níveis de 50 e $70 \%$ de sombreamento. Houve aumento na relação PA/R decorrente da adubação fosfatada, apenas na dose de 100,5 ppm, provavelmente resultante do aumento de matéria seca em manifestações epígeas, mostrando que as raízes não responderam proporcionalmente à adubação fosfatada. Da interação significativa (Tabela 6) entre os fatores adubação fosfatada e sombreamento notase, até o nível de $50 \%$ de sombreamento, as médias da relação $\mathrm{PA} / \mathrm{R}$ em tiririca não diferiram entre si com o aumento das 
TABELA 1- Resultados da análise de variância das relações $\mathrm{PA} / \mathrm{B}+\mathrm{T}+\mathrm{R}, \quad \mathrm{PA} / \mathrm{B}+\mathrm{T}, \quad \mathrm{PA} / \mathrm{R} \quad \mathrm{e}$ B+T/R. Jaboticabal, 1988/89.

\begin{tabular}{|c|c|c|c|c|}
\hline \multirow{2}{*}{ Fator de Variaçâo } & \multicolumn{4}{|c|}{ Relaçäo } \\
\hline & $\frac{\mathbf{P A}}{\mathbf{B}+\mathbf{T}+\mathbf{R}}$ & $\frac{\mathbf{P A}}{\mathbf{B}+\mathbf{T}}$ & PA/R & $\mathrm{B}+\mathrm{T} / \mathrm{R}$ \\
\hline \multicolumn{5}{|l|}{ F } \\
\hline Tratamento & $17,44^{* *}$ & $12,50^{* *}$ & $14,37^{* *}$ & $5,81^{\bullet \bullet}$ \\
\hline Sombreamento (S) & $63,87^{* *}$ & $41,97^{* *}$ & $4,37^{\circ \bullet}$ & $15,53^{* *}$ \\
\hline Adubação (A) & $9,60^{* *}$ & $8,74^{* \bullet}$ & $11,51^{* *}$ & $4,88^{* *}$ \\
\hline $\mathrm{S} \times \mathrm{A}$ & $4,59^{* *}$ & $3,93^{* *}$ & $6,82^{* *}$ & $2,87^{* *}$ \\
\hline $\mathrm{CV}(\%)$ & 27,35 & 25,96 & 41,33 & 25,69 \\
\hline DMS (S) (A) & 0,28 & 80,5 & 10,94 & 0,27 \\
\hline \multicolumn{5}{|l|}{$\mathrm{F}$} \\
\hline Ad. $0 \%$ & $0,39^{N S}$ & $0,70^{\mathrm{NS}}$ & $0,11^{\mathrm{NS}}$ & $0,43^{\mathrm{Ns}}$ \\
\hline Ad. $30 \%$ & $1,37^{\text {NS }}$ & $1,77^{\mathrm{NS}}$ & $0,79^{\mathrm{NS}}$ & $3,54^{*}$ \\
\hline Ad. $50 \%$ & $2,51^{\mathrm{NS}}$ & $2,49^{\mathrm{NS}}$ & $1,13^{\mathrm{NS}}$ & $0,28^{N s}$ \\
\hline Ad. $70 \%$ & $19,09^{* *}$ & $15,57^{* *}$ & $29,96^{* *}$ & $9,23^{* *}$ \\
\hline DMS (A d. S) & 0,57 & 61,03 & 1,94 & 0,53 \\
\hline \multicolumn{5}{|l|}{$\mathrm{F}$} \\
\hline S d. 0 ppm & $7,46^{\circ *}$ & $3,38^{\circ}$ & $2,91^{*}$ & $2,61^{\mathrm{NS}}$ \\
\hline $\mathrm{S} \mathrm{d} .33,5 \mathrm{ppm}$ & $8,82^{* *}$ & $5,17^{* *}$ & $5,22^{* *}$ & $4,00^{\circ}$ \\
\hline S d. $67,0 \mathrm{ppm}$ & $20,66^{\circ *}$ & $23,05^{* *}$ & $10,05^{* *}$ & $1,77^{\mathrm{Ns}}$ \\
\hline S d. 100,5 ppm & $40,70^{* *}$ & $22,16^{* *}$ & $42,65^{* *}$ & $15,76^{* *}$ \\
\hline DMS (S d. A) & 0,57 & 61,03 & 1,94 & 0,53 \\
\hline
\end{tabular}

- Significativo a $5 \%$ de probabilidade pelo teste F.

* Significativo a $1 \%$ de probabilidade pelo teste $\mathrm{F}$.

NS Năo significativo pelo teste $F$.

doses de $\mathrm{P}$ empregadas, sendo que esta diferença foi observada ao nível de $70 \%$ de sombreamento.

Do mesmo modo que ocorreu com a relação PA/R, constatou-se aumento na relação parte aérea / bulbos+tubérculos $(\mathrm{PA} / \mathrm{B}+\mathrm{T})$ de tiririca, nos níveis mais elevados de sombreamento $(50$ e $70 \%)$. Na Tabela 6 podese observar o aumento significativo da relação $\mathrm{PA} / 13+\mathrm{T}$ a partir do nível $50 \%$ de sombreamento. O maior valor da relação $\mathrm{PA} / \mathrm{B}+\mathrm{T}$ também foi observado na dose de 100,5 ppm de P.

A relação bulbos+tubérculos / raíz $(\mathrm{B}+\mathrm{T} / \mathrm{R})$ demonstrou uma maior suscetibilidade das raízes ao sombreamento visto que esta relação apresentou tendência de aumento com os níveis de sombreamento e, principalmente na dose de 100,5 ppm de P, causou aumento na relação bulbos+tubérculos / raíz, revelando efeito detrimental da maior dose de $\mathrm{P}$ sobre as raízes e/ou um melhor aproveitamento deste recurso por bulbos+tubérculos.

Pode-se observar, portanto, que a relação parte aérea / sistema subterrâneo (PA/B+T+R) apresentou aumento significativo com o incremento dos níveis de sombreamento,
TABELA 2 - Relações $\mathrm{PA} / \mathrm{B}+\mathrm{T}+\mathrm{R}, \mathrm{PA} / \mathrm{B}+\mathrm{T}, \mathrm{PA} / \mathrm{R}$, $\mathrm{B}+\mathrm{T} / \mathrm{R}$ obtidas pelo desdobramento da interação entre níveis de sombreamento e as doses de fósforo (média de 4 repetições). Jaboticabal, 1988/89.

\begin{tabular}{|c|c|c|c|c|}
\hline \multirow{2}{*}{$\begin{array}{c}\text { Sombrea- } \\
\text { mento } \\
(\%)\end{array}$} & \multicolumn{4}{|c|}{ Doses de $\mathbf{P}$ (ppm) } \\
\hline & $\mathbf{0}$ & 33,5 & 67,0 & 100,5 \\
\hline \multicolumn{5}{|c|}{ Relação PA/B+T+R } \\
\hline 0 & st 0,64 a & s 0,51 a & s 0,49 a & t $0,68 a$ \\
\hline 30 & t 0,38 a & s 0,79 a & s 0,70 a & t 0,71 a \\
\hline 50 & is 1,08 a & r 1,43 a & r 1,65 a & s $1,50 \mathrm{a}$ \\
\hline 70 & r $\quad 1,31$ & c r 1,39 & r 7,31 a & r $2,76 \mathrm{a}$ \\
\hline
\end{tabular}

Relação PA/B+T

\begin{tabular}{|c|c|c|c|c|}
\hline 0 & is 1,41 a & s 1,28 a & s $1,11 \mathrm{a}$ & $t 1,65$ a \\
\hline 30 & s 0,93 a & rs 1,77 a & s 1,51 a & $\mathrm{t} 1,22 \mathrm{a}$ \\
\hline 50 & r $2,05 \mathrm{a}$ & r $2,59 \mathrm{a}$ & r $3,07 \mathrm{a}$ & s $2,78 \mathrm{a}$ \\
\hline 70 & rs $1,87 \quad b$ & r $2,50 \quad b$ & r 3,90 a & r 4,10 a \\
\hline \multicolumn{5}{|c|}{ Relaçāo PA/R } \\
\hline 0 & r 1,20 a & s 0,86 a & s 0,91 a & $\mathrm{t} 1,15 \mathrm{a}$ \\
\hline 30 & r $0,67 \mathrm{a}$ & $\mathrm{s} 1,38 \mathrm{a}$ & s 1,32 a & st $1,77 \mathrm{a}$ \\
\hline 50 & r 2,28 a & r $3,39 \mathrm{a}$ & r 3,62 a & s 3,32 a \\
\hline 70 & r $2,44 \quad b$ & r $2,76 \quad b$ & r $4,18 \quad b$ & r 8,56 a \\
\hline \multicolumn{5}{|c|}{ Relaçâo B+T/R } \\
\hline 0 & r $\quad 0,88 \mathbf{a}$ & s 0,69 a & r 0,82 a & t 0,70 a \\
\hline 30 & r 0,54 b & rs 0,90 a & r 0,86 b & s 1,40 a \\
\hline 50 & r $1,20 \mathrm{a}$ & r 1,33 a & r $1,69 \mathrm{a}$ & st 1,88 a \\
\hline 70 & r $1,30 \quad b$ & rs 1,16 b & r $1,17 \quad b$ & r $2,06 \mathrm{a}$ \\
\hline
\end{tabular}

${ }^{1}$ Médias seguidas pela mesma letra náo diferem entre si pelo teste Tukey ao nivel de $5 \%$ de probabilidade, sendo:

Letras à esquerda e no sentido da coluna, comparam os diferentes níveis de sombreamento.

Letras à direita e no sentido da linha, comparam as diferentes doses de adubação.

caracterizando um maior desenvolvimento das manifestações epígeas em detrimento ao sistema subterrâneo. As doses crescentes de $\mathrm{P}$ também levaram a este resultado, porém apenas dentro do maior nível de sombreamento.

Pelos resultados observados conclui-se que o sombreamento, a níveis razoavelmente elevados (desde 50\% de interceptação), caracteriza-se como um fator de redução do desenvolvimento de plantas de tiririca, principalmente quanto à sua porção subterrânea. $\mathrm{O}$ mesmo efeito foi observado por Patterson (1982) e Jordan-Molero \& Stoller (1978), que recomendam práticas de manejo que promovam o fechamento rápido da folhagem das culturas para obtenção de sombreamento do solo. Quanto à adubação fosfatada, nota- 
se seu efeito promotor de crescimento da cyperaceae somente sob níveis baixos de sombreamento.

\section{AGRADECIMENTOS}

À FAPESP, pela concessão de Bolsa de Iniciação Científica à primeira autora.

\section{LITERATURA CITADA}

GARG, D. K. Role of environment and soil fertility in the control of nutsedge (Cyperus rotundus L.). Indian Journal of Plant Phisiology, v. 11, p. 41-49, 1968.

HOLM, L. G., PLUNCKNETT, D. L., PANCH, J. V., HERBERGER, J. P. The word's worst weeds. Honolulu: University Press of Hawaii, 1977. 607p.
JORDAN-MOLERO, J.E., STOLLER, J.E. Seasonal development of yellow and purple nutsedges (Cyperus esculentus and C. rotundus). Weed Science, v. 26, p. 614618, 1978.

MAGALHÃES, A.C. Luz no crescimento da tiririca. Bragantia, v. 26, n. 2, p. 130-141, 1967.

PARO, E.M.D. Comportamento de Cyperus rotundus $\mathbf{L}$. em diferentes condições de fertilidade do solo. Jaboticabal: FCAV/UNESP, 1977.67 p. Trabalho de Graduação em Agronomia.

PATTERSON, D.T. Comparative ecophysiology of weeds and crops. In: DUKE, S.O., ed. Weed Physiology. Boca Raton, Florida: CRC, 1984. p. 101-129.

SIRIWARDANA, G., NISHIMOTO, R. K. Propagules of purple nutsedge (Cyperus rotundus) in soil. Weed Technology, Champaign, v. 1, n. 3, p. 217-220, 1987. 